\title{
A modified Picard-Mann hybrid iterative algorithm for common fixed points of countable families of nonexpansive mappings
}

\section{Wei-Qi Deng*}

"Correspondence:

dwq1273@126.com

College of Statistics and

Mathematics, Yunnan University of

Finance and Economics, Kunming,

Yunnan 650221, P.R. China

\begin{abstract}
An up-to-date method is used for approximating common fixed points of countable families of nonlinear mappings. A modified Picard-Mann hybrid iterative algorithm is introduced with the help of our method for the class of nonexpansive mappings. Strong convergence and weak convergence theorems are established in the framework of uniformly convex Banach spaces. Our results extend the corresponding ones announced by Khan (Fixed Point Theory Appl. 2013:69, 2013, doi:10.1186/1687-1812-2013-69) to the case of countable families of nonexpansive mappings.
\end{abstract}

MSC: $47 \mathrm{H} 09 ; 47 \mathrm{~J} 25$

Keywords: Picard-Mann hybrid iteration; common fixed points; countable families of nonexpansive mappings; strong and weak convergence

\section{Introduction}

Let $K$ be a nonempty closed convex subset of a real uniformly convex Banach space $E$. A mapping $T: K \rightarrow K$ is said to be nonexpansive if

$$
\|T x-T y\| \leq\|x-y\|, \quad \forall x, y \in K .
$$

Iterative techniques for approximating fixed points of nonexpansive mappings have been studied by various authors (see, e.g., [1-5]) who used the Mann iteration process or the Ishikawa process. In 2013, Khan [6] introduced the following Picard-Mann hybrid iterative process for a single nonexpansive mapping $T$. For any initial point $x_{0} \in K$ :

$$
\left\{\begin{array}{l}
x_{n+1}=T y_{n}, \\
y_{n}=\left(1-\alpha_{n}\right) x_{n}+\alpha_{n} T x_{n}, \quad n \in \mathbb{N},
\end{array}\right.
$$

where $\left\{\alpha_{n}\right\}$ is a real sequence in $(0,1)$. He showed that the new process converges faster than all of Picard, Mann and Ishikawa iterative processes in the sense of Berinde [7] for contractions. He also proved strong convergence and weak convergence theorems with the help of his process for the class of nonexpansive mappings in general Banach spaces and apply it to obtain a result in uniformly convex Banach spaces.

C2014 Deng; licensee Springer. This is an Open Access article distributed under the terms of the Creative Commons Attribution License (http://creativecommons.org/licenses/by/2.0), which permits unrestricted use, distribution, and reproduction in any medium, provided the original work is properly cited. 
Inspired and motivated by the studies mentioned above, in this paper, we use an up-todate method for the approximation of common fixed points of countable families of nonlinear operators. We introduce a modified Picard-Mann hybrid iterative algorithm with the help of our method for the class of nonexpansive mappings. We prove strong convergence and weak convergence theorems in the framework of Banach spaces. Our results extend the corresponding ones for one map in [6].

\section{Preliminaries}

Throughout this paper we assume that $E$ is a real Banach space with its dual $E^{*}, K$ is a nonempty closed convex subset of $E$ and $J: E \rightarrow 2^{E^{*}}$ is the normalized duality mapping defined by

$$
J x=\left\{f \in E^{*}:\langle x, f\rangle=\|x\|^{2}=\|f\|^{2}\right\}, \quad \forall x \in E .
$$

In the sequel, we use $F(T)$ to denote the set of fixed points of a mapping $T$.

We say that $E$ is strictly convex if the following implication holds for $x, y \in E$ :

$$
\|x\|=\|y\|=1, \quad x \neq y \quad \Rightarrow \quad\left\|\frac{x+y}{2}\right\|<1 .
$$

It is also said to be uniformly convex if, for any $\epsilon>0$, there exists a $\delta>0$ such that

$$
\|x\|=\|y\|=1, \quad\|x-y\| \geq \epsilon \quad \Rightarrow \quad\left\|\frac{x+y}{2}\right\| \leq 1-\delta .
$$

It is well known that if $E$ is a uniformly convex Banach space, then $E$ is reflexive and strictly convex. A Banach space $E$ is said to be smooth if

$$
\lim _{t \rightarrow 0} \frac{\|x+t y\|-\|x\|}{t}
$$

exists for each $x, y \in S(E):=\{x \in E:\|x\|=1\}$. In this case, the norm of $E$ is said to be Gâteaux differentiable. The space $E$ is said to have uniformly Gâteaux differentiable norm if for each $y \in S(E)$, the limit (2.3) is attained uniformly for $x \in S(E)$. The norm of $E$ is said to be Fréchet differentiable if for each $x \in S(E)$, the limit (2.3) is attained uniformly for $y \in S(E)$. The norm of $E$ is said to be uniformly Fréchet differentiable (and $E$ is said to be uniformly smooth) if the limit (2.3) is attained uniformly for $x, y \in S(E)$.

Note The readers can find all the definitions and concepts mentioned above in [8].

A Banach space $E$ is said to satisfy Opial's condition if, for any sequence $\left\{x_{n}\right\}$ in $E, x_{n} \rightarrow x$ implies that

$$
\limsup _{n \rightarrow \infty}\left\|x_{n}-x\right\|<\limsup _{n \rightarrow \infty}\left\|x_{n}-y\right\|
$$

for all $y \in E$ with $y \neq x$, where $x_{n} \rightarrow x$ denotes that $\left\{x_{n}\right\}$ converges weakly to $x$.

A mapping $T$ with domain $D(T)$ and range $R(T)$ in $E$ is said to be demi-closed at $p$ if whenever $\left\{x_{n}\right\}$ is a sequence in $D(T)$ such that $\left\{x_{n}\right\}$ converges weakly to $x^{*} \in D(T)$ and $\left\{T x_{n}\right\}$ converges strongly to $p$, then $T x^{*}=p$. 
Remark 2.1 The following basic properties for a Banach space $E$ can be found in [9].

(i) If $E$ is uniformly smooth, then $J$ is uniformly continuous on each bounded subset of $E$.

(ii) If $E$ is reflexive and strictly convex, then $J^{-1}$ is norm-weak-continuous.

(iii) If $E$ is a smooth, strictly convex and reflexive Banach space, then the normalized duality mapping $J: E \rightarrow 2^{E^{*}}$ is single valued, one-to-one and onto.

(iv) A Banach space $E$ is uniformly smooth if and only if $E^{*}$ is uniformly convex.

(v) Each uniformly convex Banach space $E$ has the Kadec-Klee property, i.e., for any sequence $\left\{x_{n}\right\} \subset E$, if $x_{n} \rightarrow x \in E$ and $\left\|x_{n}\right\| \rightarrow\|x\|$, then $x_{n} \rightarrow x$ as $n \rightarrow \infty$.

We need the following lemmas for our main results.

Lemma 2.2 [10] Let E be a real uniformly convex Banach space and let $a, b$ be two constant with $0<a<b<1$. Suppose that $\left\{t_{n}\right\} \subset[a, b]$ is a real sequence and $\left\{x_{n}\right\},\left\{y_{n}\right\}$ are two sequences in $E$. Then the conditions

$$
\lim _{n \rightarrow \infty}\left\|t_{n} x_{n}+\left(1-t_{n}\right) y_{n}\right\|=d, \quad \limsup _{n \rightarrow \infty}\left\|x_{n}\right\| \leq d, \quad \limsup _{n \rightarrow \infty}\left\|y_{n}\right\| \leq d
$$

imply that $\lim _{n \rightarrow \infty}\left\|x_{n}-y_{n}\right\|=0$, where $d \geq 0$ is a constant.

Lemma 2.3 [11] Let E be a real uniformly convex Banach space, let $K$ be a nonempty closed convex subset of $E$, and let $T: K \rightarrow K$ be a nonexpansive mapping. Then $I-T$ is demi-closed at zero.

Lemma 2.4 [12] The unique solutions to the positive integer equation

$$
n=i+\frac{(m-1) m}{2}, \quad m \geq i, n=1,2,3, \ldots
$$

are

$$
i=n-\frac{(m-1) m}{2}, \quad m=-\left[\frac{1}{2}-\sqrt{2 n+\frac{1}{4}}\right], n=1,2,3, \ldots,
$$

where $[x]$ denotes the maximal integer that is not larger than $x$.

\section{Main results}

Lemma 3.1 Let E be a real uniformly convex Banach space and $K$ a nonempty closed convex subset of $E$. Let $\left\{T_{i}\right\}_{i=1}^{\infty}$ be a sequence of nonexpansive mappings from $K$ to itself. For an arbitrary initial point $x_{1} \in K$, the modified Picard-Mann hybrid iterative scheme $\left\{x_{n}\right\}$ is defined as follows:

$$
\left\{\begin{array}{l}
x_{n+1}=T_{i_{n}} y_{n}, \\
y_{n}=\left(1-\alpha_{n}\right) x_{n}+\alpha_{n} T_{i_{n}} x_{n}, \quad n \in \mathbb{N},
\end{array}\right.
$$

where $\left\{\alpha_{n}\right\}$ is a sequence in $[\epsilon, 1-\epsilon]$ for some $\epsilon \in(0,1)$ and $i_{n}$ is the solution to the positive integer equation: $n=i+\frac{(m-1) m}{2}(m \geq i, n=1,2, \ldots)$, that is, for each $n \geq 1$, there exists a 
unique $i_{n}$ such that

$$
\begin{array}{lll}
i_{1}=1, & i_{2}=1, \quad i_{3}=2, \quad i_{4}=1, \quad i_{5}=2, \quad i_{6}=3, \quad i_{7}=1, \\
i_{8}=2, & i_{9}=3, \quad i_{10}=4, \quad i_{11}=1, \quad \ldots .
\end{array}
$$

If $F:=\left\{x \in K: T_{i} x=x, \forall i \geq 1\right\} \neq \emptyset$, then

(1) $\lim _{n \rightarrow \infty}\left\|x_{n}-q\right\|$ exists, $\forall q \in F$;

(2) $\lim _{n \rightarrow \infty} d\left(x_{n}, F\right)$ exists, where $d\left(x_{n}, F\right)=\inf _{q \in F}\left\|x_{n}-q\right\|$;

(3) $\lim _{n \rightarrow \infty}\left\|x_{n}-T_{i} x_{n}\right\|=0, \forall i \geq 1$.

Proof (1) For any $q \in F$, by (3.1), we have

$$
\begin{aligned}
\left\|y_{n}-q\right\| & =\left\|\left(1-\alpha_{n}\right)\left(x_{n}-q\right)+\alpha_{n}\left(T_{i_{n}} x_{n}-q\right)\right\| \\
& \leq\left(1-\alpha_{n}\right)\left\|x_{n}-q\right\|+\alpha_{n}\left\|T_{i_{n}} x_{n}-T_{i_{n}} q\right\| \\
& \leq\left\|x_{n}-q\right\|,
\end{aligned}
$$

and hence

$$
\left\|x_{n+1}-q\right\|=\left\|T_{i_{n}} y_{n}-q\right\| \leq\left\|y_{n}-q\right\| \leq\left\|x_{n}-q\right\| .
$$

This shows that $\left\{\left\|x_{n}-q\right\|\right\}$ is decreasing and hence $\lim _{n \rightarrow \infty}\left\|x_{n}-q\right\|$ exists.

(2) This conclusion can easily be shown by taking the infimum in (3.3) for all $q \in F$.

(3) Assume, by the conclusion of (1), $\lim _{n \rightarrow \infty}\left\|x_{n}-q\right\|=d$. We then claim that $\lim _{n \rightarrow \infty}\left\|y_{n}-q\right\|=d$, that is,

$$
\lim _{n \rightarrow \infty}\left\|\left(1-\alpha_{n}\right)\left(x_{n}-q\right)+\alpha_{n}\left(T_{i_{n}} x_{n}-q\right)\right\|=d .
$$

In fact, noting that $\left\|x_{n+1}-q\right\|<\left\|y_{n}-q\right\|$, we have

$$
d=\liminf _{n \rightarrow \infty}\left\|x_{n+1}-q\right\| \leq \liminf _{n \rightarrow \infty}\left\|y_{n}-q\right\| ;
$$

on the other hand, it follows from (3.2) that

$$
\limsup _{n \rightarrow \infty}\left\|y_{n}-q\right\| \leq d,
$$

which implies that $\lim _{n \rightarrow \infty}\left\|y_{n}-q\right\|=d$.

Next, $\left\|T_{i_{n}} x_{n}-q\right\| \leq\left\|x_{n}-q\right\|$ implies that

$$
\limsup _{n \rightarrow \infty}\left\|T_{i_{n}} x_{n}-q\right\| \leq \limsup _{n \rightarrow \infty}\left\|x_{n}-q\right\|=d,
$$

and hence, it follows from (3.4), (3.5), and Lemma 2.2 that

$$
\lim _{n \rightarrow \infty}\left\|x_{n}-T_{i_{n}} x_{n}\right\|=0 .
$$


On the other hand, since

$$
\begin{aligned}
\left\|x_{n+1}-x_{n}\right\| & \leq\left\|x_{n+1}-T_{i_{n}} x_{n}\right\|+\left\|T_{i_{n}} x_{n}-x_{n}\right\| \\
& =\left\|T_{i_{n}} y_{n}-T_{i_{n}} x_{n}\right\|+\left\|T_{i_{n}} x_{n}-x_{n}\right\| \\
& \leq\left\|y_{n}-x_{n}\right\|+\left\|T_{i_{n}} x_{n}-x_{n}\right\| \\
& \leq \alpha_{n}\left\|T_{i_{n}} x_{n}-x_{n}\right\|+\left\|T_{i_{n}} x_{n}-x_{n}\right\|,
\end{aligned}
$$

we have, from (3.6),

$$
\lim _{n \rightarrow \infty}\left\|x_{n+1}-x_{n}\right\|=0
$$

By induction, for any nonnegative integer $p$, we also have

$$
\lim _{n \rightarrow \infty}\left\|x_{n+p}-x_{n}\right\|=0
$$

For each $p \geq 0$, since

$$
\begin{aligned}
\left\|x_{n}-T_{i_{n+p}} x_{n}\right\| \leq & \left\|x_{n}-x_{n+p}\right\|+\left\|x_{n+p}-T_{i_{n+p}} x_{n}\right\| \\
\leq & \left\|x_{n}-x_{n+p}\right\|+\left\|x_{n+p}-T_{i_{n+p}} x_{n+p}\right\| \\
& +\left\|T_{i_{n+p}} x_{n+p}-T_{i_{n+p}} x_{n}\right\| \\
\leq & 2\left\|x_{n}-x_{n+p}\right\|+\left\|x_{n+p}-T_{i_{n+p}} x_{n+p}\right\|,
\end{aligned}
$$

it follows from (3.6) and (3.8) that

$$
\lim _{n \rightarrow \infty}\left\|x_{n}-T_{i_{n+p}} x_{n}\right\|=0 .
$$

Now, for each $i \geq 1$, we claim that

$$
\lim _{n \rightarrow \infty}\left\|x_{n}-T_{i} x_{n}\right\|=0
$$

As a matter of fact, setting $n=k_{m}+i$, where $k_{m}=\frac{(m-1) m}{2}, m \geq i$, we obtain

$$
\begin{aligned}
\left\|x_{n}-T_{i} x_{n}\right\| \leq & \left\|x_{n}-x_{k_{m}}\right\|+\left\|x_{k_{m}}-T_{i} x_{n}\right\| \\
\leq & \left\|x_{n}-x_{k_{m}}\right\|+\left\|x_{k_{m}}-T_{i_{k_{m}+i}} x_{k_{m}}\right\| \\
& +\left\|T_{i_{k_{m}+i}} x_{k_{m}}-T_{i} x_{n}\right\| \\
= & \left\|x_{n}-x_{k_{m}}\right\|+\left\|x_{k_{m}}-T_{i_{k_{m}+i}} x_{k_{m}}\right\| \\
& +\left\|T_{i} x_{k_{m}}-T_{i} x_{n}\right\| \\
\leq & 2\left\|x_{n}-x_{k_{m}}\right\|+\left\|x_{k_{m}}-T_{i_{k_{m}+i}} x_{k_{m}}\right\| \\
= & 2\left\|x_{n}-x_{n-i}\right\|+\left\|x_{k_{m}}-T_{i_{k_{m}+i}} x_{k_{m}}\right\| .
\end{aligned}
$$

Note that $k_{m} \rightarrow \infty$ as $n \rightarrow \infty$. It then follows from (3.8) and (3.10) that (3.11) holds obviously. This completes the proof. 
Remark 3.2 The key point of the proof of Lemma 3.1 lies in the use of a special way of choosing the indices of involved mappings, which makes the generalization of finite families of nonlinear mappings to infinite ones possible. Moreover, with the help of our method, some known results on the common fixed points of countable families of nonexpansive mappings have been improved. We now give an example to show why our work, compared with that of others, is an improvement.

In 2011, for the approximation of common fixed points of a countable family of nonexpansive mappings $\left\{T_{n}\right\}$, Zhang et al. [13] introduced in his iterative algorithm a mapping $T$ defined by a convex linear combination of $\left\{T_{n}\right\}$, i.e., $T=\sum_{n=1}^{\infty} \lambda_{n} T_{n}, \lambda_{n} \geq 0(n=1,2, \ldots)$ with $\sum_{n=1}^{\infty} \lambda_{n}=1$. However, it is easy to see that the accurate computation of $T x_{n}$ at each step of the iteration process is not easily attainable, which will leads to gradually increasing errors. By using a special way of choosing the indices of involved mappings, Deng [14] recently improved the corresponding results announced by Zhang et al. [13]. Since the strong convergence theorems for solving some variational inequality problems and hierarchical fixed point problems are obtained without the aid of the convex linear combination of a countable family of nonexpansive mappings, our results are more applicable than those of other authors with related research interest.

Theorem 3.3 Let E be a real uniformly convex Banach space and $K$ a nonempty closed convex subset of $E$. Let $\left\{T_{i}\right\}_{i=1}^{\infty}$ be a sequence of nonexpansive mappings from $K$ to itself. Suppose that $\left\{x_{n}\right\}$ is a sequence defined by (3.1). If $F:=\left\{x \in K: T_{i} x=x, \forall i \geq 1\right\} \neq \emptyset$ and there exist $T_{i_{0}} \in\left\{T_{i}\right\}_{i=1}^{\infty}$ and a nondecreasing function $f:[0, \infty) \rightarrow[0, \infty)$ with $f(0)=0$ and $f(r)>0$ for all $r \in(0, \infty)$ such that $f\left(d\left(x_{n}, F\right)\right) \leq\left\|x_{n}-T_{i_{0}} x_{n}\right\|$ for all $n \geq 1$, then $\left\{x_{n}\right\}$ converges strongly to some common fixed point of $\left\{T_{i}\right\}_{i=1}^{\infty}$.

Proof Since

$$
f\left(d\left(x_{n}, F\right)\right) \leq\left\|x_{n}-T_{i_{0}} x_{n}\right\|,
$$

by taking $\lim \sup$ as $n \rightarrow \infty$ on both sides in the inequality above, we obtain

$$
\lim _{n \rightarrow \infty} f\left(d\left(x_{n}, F\right)\right)=0,
$$

which implies $\lim _{n \rightarrow \infty} d\left(x_{n}, F\right)=0$ by the definition of the function $f$.

Now we show that $\left\{x_{n}\right\}$ is a Cauchy sequence. Since $\lim _{n \rightarrow \infty} d\left(x_{n}, F\right)=0$, then for any $\epsilon>0$, there exists a positive integer $N$ such that $d\left(x_{n}, F\right)<\frac{\epsilon}{2}$ for all $n \geq N$. On the other hand, there exists a $p \in F$ such that $\left\|x_{N}-p\right\|=d\left(x_{N}, F\right)<\frac{\epsilon}{2}$, because $d\left(x_{N}, F\right)=\inf _{q \in F} \| x_{N}-$ $q \|$ and $F$ is closed.

Thus, for any $n, m \geq N$, it follows from (3.3) that

$$
\left\|x_{n}-x_{m}\right\| \leq\left\|x_{n}-p\right\|+\left\|x_{m}-p\right\| \leq 2\left\|x_{N}-p\right\|<\epsilon .
$$

This implies that $\left\{x_{n}\right\}$ is a Cauchy sequence, and hence there exists an $x \in K$ such that $x_{n} \rightarrow x$ as $n \rightarrow \infty$. Then $\lim _{n \rightarrow \infty} d\left(x_{n}, F\right)=0$ yields $d(x, F)=0$. Further, it follows from the closedness of $F$ that $x \in F$. This completes the proof. 
Theorem 3.4 Let E be a real uniformly convex Banach space satisfying Opial's condition and $K$ a nonempty closed convex subset of $E$. Let $\left\{T_{i}\right\}_{i=1}^{\infty}$ be a sequence of nonexpansive mappings from $K$ to itself. Suppose that $\left\{x_{n}\right\}$ is a sequence defined by (3.1). If $F:=\{x \in K$ : $\left.T_{i} x=x, \forall i \geq 1\right\} \neq \emptyset$, then $\left\{x_{n}\right\}$ converges weakly to some common fixed point of $\left\{T_{i}\right\}_{i=1}^{\infty}$.

Proof For any $q \in F$, by Lemma 3.1, we know that $\lim _{n \rightarrow \infty}\left\|x_{n}-q\right\|$ exists. We now prove that $\left\{x_{n}\right\}$ has a unique weakly subsequential limit in $F$. First of all, Lemmas 2.3 and 3.1 guarantee that each weakly subsequential limit of $\left\{x_{n}\right\}$ is a common fixed point of $\left\{T_{i}\right\}_{i=1}^{\infty}$. Secondly, Opial's condition guarantees that the weakly subsequential limit of $x_{n}$ is unique. Consequently, $\left\{x_{n}\right\}$ converges weakly to a common fixed point of $\left\{T_{i}\right\}_{i=1}^{\infty}$. This completes the proof.

Remark 3.5 The results presented in this paper extend those of Khan [6], whose research areas are limited to the situation of a single nonexpansive mapping.

Competing interests

The author declares that they have no competing interests.

\section{Acknowledgements}

The author is very grateful to the referees for their useful suggestions, by which the contents of this article has been improved. This work is supported by the National Natural Science Foundation of China (Grant No. 11061037).

Received: 25 April 2013 Accepted: 25 February 2014 Published: 06 Mar 2014

References

1. Chang, SS, Cho, YJ, Zhou, H: Demi-closed principle and weak convergence problems for asymptotically nonexpansive mappings. J. Korean Math. Soc. 38, 1245-1260 (2001)

2. Ishikawa, S: Fixed points and iteration of a nonexpansive mapping in a Banach space. Proc. Am. Math. Soc. 73, 61-67 (1967)

3. Oslike, MO, Udomene, A: Weak and strong convergence theorems for fixed points of asymptotically nonexpansive mappings. Math. Comput. Model. 32, 1181-1191 (2000)

4. Schu, J: Iterative construction of fixed points of asymptotically nonexpansive mappings. J. Math. Anal. Appl. 158, 407-413 (1991)

5. Xu, HK, Ori, R: An implicit iterative process for nonexpansive mappings. Numer. Funct. Anal. Optim. 22, 767-773 (2001)

6. Khan, SH: A Picard-Mann hybrid iterative process. Fixed Point Theory Appl. 2013, Article ID 69 (2013). doi:10.1186/1687-1812-2013-69

7. Berinde, V: Iterative Approximation of Fixed Points. Editura Efemeride, Baia Mare (2002)

8. Takahashi, W: Nonlinear Functional Analysis. Fixed Point Theory and Its Applications. Yokohama Publishers, Yokohama (2000)

9. Cioranescu, I: Geometry of Banach Spaces, Duality Mappings and Nonlinear Problems. Kluwer Academic, Dordrecht (1990)

10. Schu, J: Weak and strong convergence of fixed points of asymptotically nonexpansive mappings. Bull. Aust. Math. Soc. 43, 153-159 (1991)

11. Górnicki, J: Weak convergence theorems for asymptotically nonexpansive mappings in uniformly convex Banach spaces. Comment. Math. Univ. Carol. 30, 249-252 (1989)

12. Deng, WQ, Bai, $P$ : An implicit iteration process for common fixed points of two infinite families of asymptotically nonexpansive mappings in Banach spaces. J. Appl. Math. 2013, Article ID 602582 (2013)

13. Zhang, SS, Wang, XR, Lee, HWJ, Chan, CK: Viscosity method for hierarchical fixed point and variational inequalities with applications. Appl. Math. Mech. 32(2), 241-250 (2011). doi:10.1007/s10483-011-1410-8

14. Deng, WQ: New viscosity method for hierarchical fixed point approach to variational inequalities. Fixed Point Theory Appl. 2013, Article ID 219 (2013). doi:10.1186/1687-1812-2013-219 